Alumbrado, limpieza y recogida de basuras en La Habana de Ezpeleta: bandos y reglamento (1786-1787)

Eduardo Azorín García

Universidad Pablo de Olavide (España) 



\title{
Alumbrado, limpieza y recogida de basuras en La Habana de Ezpeleta: bandos y reglamento (1786-1787) ${ }^{1}$
}

\section{Lighting, cleaning and garbage collection in La Habana de Ezpeleta: sides and regulation (1786-1787)}

\author{
Eduardo Azorín García \\ Universidad Pablo de Olavide (España) \\ eduardoazorinam@gmail.com
}

Fecha de recepción: 10 de diciembre de 2020

Fecha de aceptación: 10 de abril de 2021

\begin{abstract}
Resumen
La ciencia de la policía y los preceptos ilustrados sobre urbanismo llegaron a La Habana, como en el resto de la monarquía hispánica, en la segunda mitad del siglo XVIII. Esta coyuntura dejó como testimonio una serie de documentos normativos de carácter ejecutivo que emanaban directamente del poder local y regulaban prácticas y aspectos de orden público en el entorno urbano para un mayor control de la población. Desde esta perspectiva, en este artículo se analizan tres bandos y un reglamento que dictaron la implementación del alumbrado público y de un sistema de limpieza y recogida de basuras en La Habana durante el mandato del gobernador José Manuel de Ezpeleta.
\end{abstract}

Palabras clave: La Habana; José Manuel de Ezpeleta (1739-1823); Siglo XVIII; Policía; Bandos; Higiene.

\begin{abstract}
The science of the police and the enlightened precepts on urbanism arrived in Havana, as in the rest of the Hispanic monarchy, in the second half of the 18th century. This situation left as testimony a series of normative documents of an executive nature which emanated directly from the local power and regulated practices and aspects of public order in the urban environment for a greater control of the population. From this perspective, this article analyzes three bandos and a rule that dictated the implementation of public lighting and a system of cleaning
\end{abstract}

1 Trabajo realizado en el marco del proyecto de investigación El orden y sus desafios en el Circuncaribe hispano, 1791-1960 (RTI2018-094305-B-I00PHAHIS6) financiado por el Ministerio de Ciencia e Innovación, dirigido por la Dra. Consuelo Naranjo Orovio desde el Instituto de Historia-CSIC. 
Alumbrado, limpieza y recogida de basuras en La Habana... - E. Azorín García

and garbage collection in Havana during the term of governor José Manuel de Ezpeleta.

Keywords: Havana; José Manuel de Ezpeleta (1739-1823); 18th century; Police; Bandos; Hygiene.

\section{UNA APROXIMACIÓN AL ENTORNO URBANO DE LA HABANA}

Hacia la segunda mitad del siglo XVIII la apariencia urbana de La Habana era muy deslucida a pesar de su condición capitalina, de la alta densidad de población ${ }^{2}$ y de ser uno de los puertos comerciales más importantes de la América hispana. Los principales problemas que presentaba la ciudad eran la carencia de mobiliario urbano generalizado y la falta de higiene en la vía pública, situación que dificultaba la buena habitabilidad de los vecinos y ofrecía un aspecto de desorden (Amores Carredano, 2000, p. 104). Sin embargo, desde 1763 -una vez recuperada La Habana de la toma británica-, se dio inicio a una estrategia normativa con el fin de "ordenar y regular la vida comunal [de la ciudad] por medio de Bandos, sobre todo los llamados de Buen Gobierno" (Riverend, 1992, p. 124).

En tal sentido, en la década de 1770 se impulsó una fase de remodelación urbana de la mano del gobernador de La Habana Felipe de Fonsdeviela, Marqués de la Torre (1771-1777); propósito que fue prosperando paulatinamente con el paso de sus sucesores. El Marqués favoreció la proliferación de edificaciones civiles, incorporó una serie de equipamiento urbano y conformó nuevos lugares de esparcimiento (Apaolaza Llorente, 2016, p. 121 y ss.). No obstante, algunas cuestiones de la voluntad de Fonsdeviela no llegaron a tomar forma. Dado su carácter ilustrado formó una Instrucción Política para "su hijo en policía" José Manuel de Ezpeleta, quien ejerció años después la gobernación de La Habana (1785-1790) ${ }^{3}$, con el objetivo de que prosiguiera determinados puntos de orden público ${ }^{4}$. Entre numerosos asuntos, con el fin de ofrecer comodidad y seguridad a la población, sugirió "la colocación de faroles por todas las calles"; e igualmente, hizo palpable la necesidad de mejorar la imagen urbana y preservar la limpieza "en el recinto de la Ciudad" (Amores Carredano, 2019, pp. 127,129 y 131). En consecuencia, hacia finales de 1786, Ezpeleta estableció una red de alumbrado urbano y un sistema de limpieza y recogida de basuras, ambos de carácter público y generalizado, a partir de la expedición de una serie de bandos particulares de policía.

2 En 1787 se estiman alrededor de 49.000 habitantes en el recinto intramuros, cifra sólo superada entonces en los territorios hispanoamericanos por México o Lima (Amores Carredano, 2000, p. 32).

3 Para una visión amplia de su mando en la Gobernación de La Habana y Capitanía General de la Isla de Cuba: (Amores Carredano: 2000).

4 La Instrucción política que desde la eternidad remitió el Marqués de la Torre a su querido hijo, en policía, el brigadier Don José Ezpeleta, Gobernador de La Habana se trata de un manuscrito inédito en su carácter y estilo que localizó el Dr. Juan Bosco Amores Carredano en la Biblioteca Histórica Municipal de Madrid. 


\section{POLICÍA Y GIUDAD}

La ciencia de la policía fue una doctrina que surgió del cameralismo ${ }^{5}$ en el transcurso de la formación del estado absolutista entre los siglos XVI y XVIII. Tuvo un importante desarrollo de su concepto en la tratadística europea ${ }^{6}$ de este espacio temporal, en la que fue dotada de una sucesión de características y funciones muy concretas. Además de ser uno de los mecanismos por los cuales se aseguraba el incremento de las fuerzas de la monarquía y la conservación del orden, fue reconocida principalmente por su actuación en el ámbito urbano (Anguita Cantero, 1997, p. 107; Foucault, 2006, pp. 357 y 376; Guerrero, 1986, pp. 36, 43, 57 y 78). A grandes rasgos, la policía intervenía regulando la "vida cotidiana" de las ciudades a través del control de los individuos y sus actividades para garantizar el orden y el bienestar público. Mediante este procedimiento de supervisión social se pretendía difundir una serie de "actitudes disciplinadas" basadas en el obedecimiento, la moral y la religión. La contravención de las pautas establecidas era perseguida y castigada con el fin de alcanzar el correcto funcionamiento de la vida diaria y la instauración de una buena convivencia (Fraile, 1997, pp. 24-27). Asimismo, la policía fue también una entidad garante y difusora de los preceptos del urbanismo ilustrado, todo un aval en el propósito de mejorar la habitabilidad de la ciudad. La salubridad, la seguridad, el abasto de aguas y víveres, el embellecimiento y ordenamiento de la vía pública, entre otras, también fueron materia de policía. El interés de esta disciplina residió en otorgar comodidad y felicidad a los vecinos a través de las mejoras realizadas en el medio urbano (Anguita Cantero, 1997, pp. 106-109; Fraile, 1997, p. 24).

Generalmente el gobierno local -en determinadas ocasiones autoridades superiores- tenía encomendadas las facultades de policía. De este modo, en los territorios de la monarquía hispánica eran los cabildos los encargados de reglamentar las funciones que propiciaba la vida social y económica de la ciudad. El poder municipal tenía que tener conocimiento de las actividades que se llevaban cabo para ejercer un control sobre ellas. La presencia de la policía debía de ser constante y minuciosa a fin de garantizar el orden de la manera más activa. En tal forma, los tratadistas de la época recomendaban la institución de subalternos que de forma práctica y preventiva profesasen la vigilancia de las normas de policía. En el caso español, estos delegados de policía aparecieron con el nombre de comisarios de

5 El cameralismo fue el cuerpo doctrinal de las ciencias administrativas en la que los diversos reinos centroeuropeos conformaron progresivamente su poder efectivo y central a través de la ordenación de sus territorios. Para mayor desarrollo del concepto véase: (Guerrero, 1986).

6 Cabría destacar por su influencia el Tratado de Policía de Nicolás Delamare, publicado en 6 tomos entre 1705 y 1738; y Principios de Ciencia de la Policía de Juan Enrique Amadeo von Justi, editado en 1756. En España también hubo una serie de tratadistas que abordaron la ciencia de la policía desde la segunda mitad del Setecientos, entre otros Valentín de Foronda o Antonio Francisco Puig y Gelabert. Para profundizar consúltese: (Fraile, 1997, pp. 103 y ss.). 
barrio $^{7}$. Las ciudades se dividieron en cuarteles, y a su vez, los cuarteles en barrios; es decir, circunscripciones administrativas menores donde establecer a estos agentes para ejercer un mayor control en los asuntos de policía (Anguita Cantero, 1997, pp. 119 y 120; Fraile, 1997, p. 24; Vallejo Fernández, 2008, pp. 130-133).

La regulación normativa de la policía en la vida urbana no se adscribe a una perspectiva judicial o de leyes generales. La autoridad municipal o competente emitía, publicaba y difundía una serie de documentos dispositivos -tales como los bandos o los reglamentos- que se comprendían dentro del derecho de naturaleza ejecutiva. Estos tenían un carácter diligente, minucioso, variable y renovador según las eventualidades cotidianas. Por lo cual, la policía se encargaba del detalle de una realidad urbana muy concreta (Fraile, 1997, pp. 24 - 25; Godicheau, 2013, p. 112; Vallejo Fernández, 2008, p. 134). En relación a estas disposiciones la policía también abordaba de manera fundamental la cuestión "pública", concebida dentro del Antiguo Régimen como un asunto moral en el que lo "particular" quedaba supeditado al "bien común". En la instauración del orden se justificaba la primacía de lo público - por ejemplo: seguridad, tranquilidad o salud- en detrimento del interés individual. En otras palabras, los sujetos quedaban relegados a una especie de acuerdo y obligaciones en subordinación del bienestar general y el orden público (Godicheau, 2013, pp. 115, 116 y 118; Lempérière, 2008, p. 35).

La ciencia de la policía y la Ilustración aunque eran materias distintas estaban intensamente asociadas. El siglo XVIII trajo consigo un importante crecimiento de la población y en consecuencia, la dilatación de los núcleos urbanos. Las ciudades debían enfrentarse a una serie de nuevos retos, para los cuales, los preceptos ilustrados de la monarquía se sirvieron de las disposiciones de policía para ordenar, controlar e impulsar las obras públicas y el embellecimiento de las ciudades. La corona emprendió en la península y en América una política de carácter iluminista para ejecutar reformas en las principales capitales. El ideal medió en la imposición de una buena imagen urbana a partir de la comodidad, el orden y la higiene en una concepción extensiva a toda la población. El propósito se procuró mediante la gestión racional del espacio -regulación y ornato de la vía pública, creación de espacios recreativos o naturales, etc.- y con la provisión de mobiliario y servicios urbanos - empedrado, alumbrado, alcantarillado, recogida de basuras, etc. -, a fin de mejorar la calidad de habitabilidad de las ciudades (Alzate Echeverri, 2007, pp. 42 y 43; Anguita Cantero, 1997, p. 106 y 118; Fraile, 1997, pp. 24, 75 y ss; Gutiérrez, 2010 , p. 225). Dentro de esta coyuntura, en el empeño por la seguridad pública

7 La figura de los comisarios de barrio apareció en La Habana de forma prematura en 1763. El entonces Gobernador de La Habana, Conde de Ricla (1763-65), expidió un Reglamento de Policía por el que se dividía la ciudad en cuarteles y barrios, se daba nomenclatura a calles y casas, e instauraba a estos delegados de policía bajo una serie de instrucciones. Con posterioridad, el reglamento se renovó durante el mando de Antonio María Bucareli (1766-71). También hubo una nueva propuesta de la mano de José de Ezpeleta al cuestionar la efectividad de estos agentes. Para una perspectiva más amplia de los comisarios de barrio en La Habana, véase: (Apaolaza Llorente, 2015; Godicheau, 2017). 
surgió la instalación sistemática de iluminación urbana. Desde los tiempos de la ciudad antigua había sido conveniente el establecimiento voluntario de luz en las horas nocturnas, sin embargo, hasta las últimas décadas del siglo XVIII no aparece un sistema de alumbrado público. La estructura elemental consistía en la instalación de faroles de hierro y cristal con candelas - $\mathrm{o}$ en su defecto una provisión de aceite como combustible que se adherían a los muros de las casas (Segarra Lagunes, 2012, pp. 16, 35 y 94). La noche y la oscuridad siempre habían sido concebidas como fuente de peligro y horrores, empero, la iluminación por toda la vía pública junto a las disposiciones que restringían determinadas actividades en horas definidas de la noche vislumbraron el control racional del ámbito urbano nocturno (Martínez Gomis, 2003, pp. 149, 150 y 168). El alumbrado se concibió como un símbolo de progreso y civilización que otorgaba seguridad, orden y concordancia a la moral declarada. Del mismo modo, concedía un grado de estética y decoro práctico a la ciudad (Alzate Echeverri, 2007, pp. 127-129).

La policía también se ocupó de las cuestiones concernientes a la higiene y la salubridad urbana formando un dispositivo higiénico en el medio de la ciudad para la preservación de sus habitantes (Jori, 2013, p. 150). La estrategia de actuación se basó en la teoría mecanicista del aire ${ }^{8}$ que tenía como hipótesis que este fluido vital era pertinente de ser alterado si se estancaba y dejaba de circular. El aire en movimiento sugería renovación y pureza, mientras que el aire estático se consideraba nocivo por la influencia que ejercían el clima y los cuerpos vivos sobre él. La climatología condicionaba las características del aire, y según esta teoría, se debía buscar el equilibrio para el buen funcionamiento del sistema vital de los seres vivos. Una zona excesivamente calurosa propiciaba un ambiente que favorecía la dilatación de los cuerpos y la obstrucción de su tránsito interno. Las altas temperaturas favorecían el estatismo del aire, mientras que las zonas frescas atemperadas eran más adecuadas para la vida y para el movimiento. Lo mismo ocurría con la humedad ya que retenía la elasticidad del aire. En tal sentido, los facultativos recomendaban que las ciudades debían de establecerse en latitudes adecuadas y poseer calles anchas y rectas (Corbin, 1987, p. 19; Dávalos, 1997, pp. 33, 36, 40 y 41; Etlin, 1997, pp. 123 125). El aire también podía ser perturbado por las emanaciones y exhalaciones de la materia orgánica. Los "miasmas" que desprendían los cuerpos animales hacinados, enfermos o en descomposición; la corrupción de los vegetales; las aguas estancadas y los suelos lodosos se consideraban como auténticas fuentes de peligro capaces de infectar el aire y generar enfermedad y muerte. Precisamente, las patologías y las epidemias se explicaban en esta época a raíz del aire estancado y contaminado en un espacio. En los centros urbanos la falta de higiene en la vía pública hacía patente

8 Esta teoría surgió del mecaniscismo, que fue una corriente científica del siglo XVIII en la que la naturaleza se explicaba de forma racionalizada a partir de los principios mecánicos del movimiento (Dávalos, 1997, pp. 33 y 36). 
la existencia de charcos, barrizales y residuos orgánicos que turbaban los aires ${ }^{9}$. Es así que las principales fórmulas de "saneamiento ambiental" de la ciudad pasaron por ventilar y purificar el aire, y en este sentido, la ciencia de la policía hizo especial hincapié en la limpieza de las calles y la recolección sistematizada de basuras para evitar todos los problemas que podía suscitar la corrupción del aire (Corbin, 1987, pp. 23, 31, 41, 105; Reguera Rodríguez, 1992, p. 111).

\section{LOS BANDOS PARTICULARES DE EZPELETA}

Entre 1786 y 1787 el gobernador de La Habana José Manuel de Ezpeleta emitió tres bandos particulares de policía que disponían la instauración de un sistema de alumbrado y de recogida de basuras. Estas resoluciones normativas se encuadran en el escenario hispanoamericano de la segunda mitad del siglo XVIII en el que los bandos, tanto los ordinarios como los de buen gobierno, comienzan a proliferar. Ambas tipologías fueron una herramienta al servicio del despotismo ilustrado para garantizar el control y disciplina de una sociedad cada vez más compleja y en constante crecimiento (Apaolaza Llorente, 2016, pp. 65 y ss; Escobedo Mansilla, 1995, pp. 473 y 483).

Antes deanalizar las disposiciones deEzpeleta, es precisohacerunadiferenciación de lo que se conoce como bandos de buen gobierno ${ }^{10} \mathrm{y}$ bandos comunes ${ }^{11}$. Los bandos de buen gobierno son "un mandamiento de autoridad competente dirigido a todos los vecinos y habitantes de la ciudad y su jurisdicción, que contiene un conjunto articulado de disposiciones sobre diversas materias relativas a la vida local, que se daba a conocer públicamente a toda la población" (Tau Anzoátegui, 2004, p. 17). Por el contrario, los bandos particulares son "textos de extensión reducida, en los que las disposiciones están formuladas de manera sencilla y recurrente, las temáticas sobre las que legisla son relativas a situaciones cotidianas de la comunidad urbana y sus

9 Si atendemos a la teoría mecaniscista del aire la ciudad de La Habana hubiese sido un espacio prácticamente inhabitable. En esta línea, hubiese predominado el aire estático debido a la configuración de la traza por calles estrechas y algo tortuosas, al estar cercada por una muralla que no permitiría la correcta circulación del aire, a la indiscutible falta de higiene, y más si cabe, al encontrarse en una latitud con un clima muy caliente y húmedo.

10 El estudio de los bandos de buen gobierno en América fue impulsado especialmente por el historiador y jurista Tau Anzoátegui, centrado en el ámbito argentino (1983 y 2004). Para los bandos de buen gobierno en Cuba es esencial la consulta de la obra de Apaolaza Llorente (2016).

11 Los bandos comunes aparecen usualmente en la documentación primaria bajo la definición simple de "bandos". En algunas ocasiones se les refiere como "autos", "edictos" o "decretos", entendiéndose que han sido exhibidos como bandos, es decir, se han hecho públicos a todos los habitantes de la ciudad. No obstante, la historiografía ha dotado de apellido a este documento para diferenciarlo de los "bandos de buen gobierno". Se pueden encontrar citados como "bandos ordinarios", "bandos singulares" (Tau Anzoátegui, 1983, pp. 93 y 100), "bandos particulares" (Escobedo Mansilla, 1995, p. 483), "textos satélites", "bandos corrientes" (Tau Anzoátegui, 2004, p. 18) y "bandos sueltos" (Apaolaza Llorente, 2016, p.88). En el presente texto aparecerán mencionados de forma alterna. 
instrucciones implican a todos los miembros de la sociedad" (Sidy, 2011, p. 122). Como se puede ver, ambos niveles documentales responden a una misma naturaleza legislativa local y pública. Esto quiere decir que la materia dispositiva se elabora según la casuística del medio urbano y para la extensión de todos sus integrantes sin diferenciación social o de fuero. Sin embargo, la principal disimilitud entre los dos modelos es la extensión de su formato y la cuantía de las normas: mientras el bando de buen gobierno congrega una amplia y diversa agrupación de dictados de policía, el bando ordinario se concentra en una o dos cuestiones a lo sumo, las cuales detalla de manera más holgada. En contraste, cabe decir que el bando común era un nivel inferior en la presente tipología documental. Servía usualmente a modo de complemento o aclaración de los autos de buen gobierno, de esta forma, solo de forma ocasional contribuía con mandamientos inéditos (Tau Anzoátegui, 2004, p. 18).

En el caso de la estructura formal de los documentos, la categorización señalada por Tau Anzoátegui ${ }^{12}$ para los bandos de buen gobierno (1983, pp. 2004, pp. 61 y ss.) también es aplicable a los bandos particulares. A pesar de ello, y en consonancia con Sidy (2010, pp. 127-129), los bandos ordinarios destacan por presentar una cláusula introductoria más prolongada con una descripción minuciosa del tema en cuestión dada su puntualidad. Cabe añadir que la cláusula introductoria, como parte articuladora del cuerpo textual, también se caracteriza comúnmente por ser más densa que cada uno de los puntos presentados en los bandos de buen gobierno. De tal forma, se puede considerar que un estudio conjunto de bandos particulares durante un determinado periodo permitiría brindar una amplificación de la realidad urbana en aspectos muy concretos.

En lo que se refiere a la emisión, publicación, vigencia y penas de la normativa también existen semejanzas y diferencias. Los dos tipos de bandos eran promulgados por la autoridad competente en materia de policía. Normalmente, estos asuntos eran facultad del poder municipal, empero, en los principales centros urbanos los jefes delegados de la corona-virreyes, gobernadores o corregidores- tenían la potestad de dictar este tipo de mandatos (Dougnac Rodríguez, 1994, pp. 12, 13, 108 y 122). En este punto, la distinción estribaba en que los bandos comunes se expedían con una considerable continuidad. Estos eran más inmediatos a la casuística y no respondían a una eventualidad de la vida política. Al contrario, los bandos de buen gobierno eran más exclusivos en tanto que de manera genérica se despachaban al inicio de la comisión gubernativa de la autoridad de turno (Sidy, 2010, p. 123). Por otra parte, ninguno de los dos necesitaba refrenda real porque las atribuciones de policía posibilitaban la expedición de este tipo de normas a los jefes locales o provinciales. En cuanto a la publicación de estos modelos legislativos, debido a que la noción "bando" implicaba publicidad y era su cometido hacer llegar la orden a toda la

12 Intitulación -nombre y título de la autoridad que lo emitía -, cláusula introductoria - destino e intención-, cláusulas dispositivas -normas imperativas articuladas-, cláusula penal -penas por contravenir la normal-, y cláusula final -disposición de publicación, rúbrica, lugar y fecha-. 
extensión del vecindario, se procedía a la realización de un acto solemne en la vía pública. Con este pregón se intentaba informar al grueso del pueblo analfabeto, y además, para la ratificación del acontecimiento se fijaban los bandos en los lugares más visibles de la ciudad. La exclusividad del bando de buen gobierno dotaría a esta ceremonia de mayor pompa (Tau Anzoátegui, 2004, pp. 58-60). Acerca de la vigencia de ambos documentos dispositivos no existía una pauta explícita que estableciese una caducidad en la validez. Por un lado, los bandos de buen gobierno se caracterizaban por la acumulación, esto quiere decir, que por cada jefe de gobierno se repetían y renovaban las normas mientras se podían añadir nuevas implicando la acumulación reglamentaria ${ }^{13}$ (Tau Anzoátegui, 2004, p. 109). Por otro lado, los bandos particulares al tratar de cuestiones puntuales colaboraban en la citada acumulación a modo de suplemento pero también, dada la minuciosidad de los asuntos que abordaban, si lo ordenado quedaba cumplido podían darse por prescritos. Por último, cabe señalar que las penas que aparecían en estos moldes legislativos eran las mismas -"corporales, infamantes y pecuniarias" (Tau Anzoátegui, 1983, p. 132)-. En el caso del bando común el castigo empleado por contravención dependerá de la temática tratada en el mismo, al igual que ocurría en cada artículo de los bandos de buen gobierno.

Expuesto lo anterior, es preciso pasar a analizar los bandos de Ezpeleta en materia de iluminación y limpieza. Estas disposiciones respondieron a las evidentes carencias que albergaba la capital cubana con respecto a la vigilancia nocturna, el ornato y la higiene. Antes de la llegada de este gobernador la ciudad no contaba con un alumbrado extensivo a toda la vía pública, solamente los edificios principales y los establecimientos públicos estaban obligados a prender un farol en las horas de oscuridad. Además, una gran parte de los vecinos habaneros mantenían una serie de costumbres perjudiciales con respecto a la evacuación de las basuras domésticas en la propia calle. (Apaolaza Llorente, 2018, pp. 72 y 74). Ezpeleta al publicar su bando de buen gobierno ${ }^{14}$ se limitó mayormente a reiterar las órdenes anteriores en materia de seguridad y salubridad. No obstante, añadió un artículo -el número 34- en el que prohibía arrojar deshechos a la vía pública, los cuales debían ser trasladados a los "parajes señalados", y compelió a barrer y regar el frente de los hogares de los vecinos. Muy pronto comprendió las necesidades que le había trasladado el Marqués de la Torre en su Instrucción y se vio en la alternativa de intervenir con más diligencia mediante la expedición de bandos singulares.

13 Apaolaza Llorente (2016, p. 86) considera que los bandos de buen gobierno en Cuba tenían una "caducidad estipulada" en tanto que el último bando publicado "era con el que se regían los ministros de justicia encargados de hacerlos cumplir".

14 Bando de buen gobierno del gobernador Ezpeleta. La Habana, 1 de febrero de 1786. Archivo General de Indias (AGI), Audiencia de Santo Domingo (SD), Legajo 1431 en: (Apaolaza Llorente, 2016, pp. 457-469). 
El gobernador de La Habana publicó su primer bando particular ${ }^{15}$ al respecto a finales de 1786. La motivación de la materia fue muy clara: "La incomodidad y desorden que ocasiona la oscuridad y lo que padecen las ciudades por falta de limpieza en las casas y calles es patente en todo el mundo". En esta corriente, el documento apuntó el compromiso que existía de situar a la capital cubana en la misma calidad que las principales ciudades europeas y americanas a partir de la instauración de un sistema de alumbrado y de recogida de basuras. Para ello, todos los vecinos "sin excepción de fueros o personas" debían contribuir desde noviembre del citado año con una cuota mensual de tres reales y medio para las casas principales y de dos reales por cada accesoria. La red de iluminación se compondría a partir de faroles de hierro y cristal con candelas internas que se distribuirían sistemáticamente por todas las cuadras de la vía pública. Una cuadrilla de dependientes se encargaría de encender las lamparillas diariamente, a la hora determinada, haciendo uso de escaleras y pescantes ${ }^{16}$. En cambio, en relación a la recolección de los desperdicios domésticos, se fijó una contrata con un particular que debía de gestionar el acopio de las basuras. El sistema sería dotado de unos carros que trasladarían la basura a extramuros de la ciudad, igualmente, en los "parajes destinados". Como se puede advertir, tanto el artículo 34 del bando de buen gobierno como este bando común hacen presente una zona concreta donde depositar la basura, que al parecer, era conocida por todo el vecindario ya que no se indica el lugar de forma explícita. No obstante, existía un bando ordinario anterior - de 9 de junio de 1770- que ayuda a comprender esta cuestión. Proveía que los residuos que sacasen los vecinos debían ser depositados en las canteras abiertas que existían en el Partido de San Lázaro. Las guardias de las puertas de la muralla tenían que celar que solo se retirase la basura de la plaza por la Puerta de la Punta y que no se arrojasen en el foso de la defensa ${ }^{17}$.

En cuanto a este primer bando particular de Ezpeleta también se hace un llamamiento a la colaboración de los habitantes de la ciudad -algo muy propio de los principios de policía- con respecto a la limpieza y el tratamiento de los desechos. Los vecinos tenían que asear el interior de su hogar pero también el frente de la calle correspondiente al inmueble. De esta manera se amontonaban los residuos dentro de la vivienda a la espera de escuchar la campana del carro recolector para poder retirarla. Aquí se hace evidente el precepto ilustrado del beneficio común produciéndose una articulación en la limpieza del espacio público y el privado. El bando mandaba limpiar las calles pero también el interior del domicilio en una primacía del interés general por conservar una atmósfera purificada. Atendiendo a la teoría mecanicista del aire se entiende que las emanaciones y exhalaciones de una

15 Bando particular del gobernador Ezpeleta. La Habana, 30 de octubre de 1786. AGI, Papeles de Cuba (PC), Legajo 1407.

16 Oficio de José de Ezpeleta al regidor Gabriel Peñalver y Cárdenas. La Habana, 20 de julio de 1786. AGI, Papeles de Cuba (PC), Legajo 1401.

17 Oficio del Marqués de la Torre al Comandante de la Guardia de la Puerta de la Punta. La Habana, 22 de Junio de 1773. AGI, PC, Legajo 1228. 
sola morada podrían producir una enfermedad infecciosa al corromper el ambiente de la ciudad. En relación a ello, la red de limpieza no atendía el transporte de muebles, arenas o escombros de obras, "sino lo que diariamente produce el manejo económico de las casas y sus caballos o mulas", es decir, los residuos orgánicos pertinentes de descomponerse.

El objetivo principal del bando era tener las calles y plazas limpias al iniciar el año de 1787. Por el contrario, el alumbrado tardaría en llegar un tiempo, por lo menos hasta que el acopio de los "faroles, pescantes y escaleras" fuese suficiente para proceder a su instalación. Cabe resaltar que este bando común no contiene una cláusula penal para aquellos que no hiciesen efectiva la imposición. Esto hace pensar que es posible que la autoridad tuviese especial confianza en la plena participación de la población debido al interés general que suscitaba. Es más, la propia superioridad gubernativa se determinó a ser la primera en aportar el impuesto mensual "para ejemplo y estímulo de las demás [casas]". Sin embargo, con el paso de las primeras semanas Ezpeleta percibió dificultades para costear ambos servicios urbanos con la tasa impuesta (Amores Carredano, 2000, pp. 374-377). No todos los residentes estuvieron prestos a pagar la contribución, además, la conducta de los vecinos con respecto a arrojar los desechos en la vía pública no había variado. En esta coyuntura dio inicio 1787 y no se cumplió el fin del bando: La Habana conservaba su aspecto de suciedad e incluso empeoró. Dadas las circunstancias, el gobernador volvió a publicar un segundo bando ${ }^{18}$ particular a las pocas semanas de haber comenzado el año.

El nuevo bando singular contenía una cláusula introductoria bastante amplia en la que precisaba los problemas y las causas que llevaban a la expedición de una nueva norma junto con la renovación de la anterior. En un tono más severo condenaba la falta de asistencia de los habitantes en el pago -bien por no querer o bien por no poder-, la inoperancia en el ejercicio de la limpieza y la continuidad en la práctica de tirar residuos en la calle. Esta actitud de los vecinos entorpecía la eficiencia del sistema establecido. Ezpeleta no solo apeló a la "salud pública" desde una perspectiva paternalista - puesto "que ningún habitante sabrá cuidar[la] como el Superior Gobierno"-, sino que advirtió sobre el problema que sacudía la integridad del puerto. Una de las grandes preocupaciones de la ciudad en esta época fue el resguardo de la conservación del fondo de la bahía. Las basuras vertidas en la vía pública, a las que se sumaban arenas, piedras y todo tipo de restos orgánicos en descomposición, acababan desembocando de manera continua en el interior de la bahía en los días de fuertes lluvias. Las autoridades vigilaban constantemente para que el calado del puerto estuviese navegable debido a que existía el miedo de que la solidificación de las basuras cegase el fondo y no posibilitase la entrada y salida de los barcos con mercancías. Desde la década de 1770 se intentó poner remedio a esta cuestión mediante diversas proposiciones: la construcción de cloacas que

18 Bando particular del gobernador Ezpeleta. La Habana, 28 de enero de 1787. AGI, PC, Legajo 1407. 
desaguasen fuera del puerto, la instauración de pontones y gánguiles que limpiasen el calado de la bahía o un proyecto de empedrado de calles que retuviesen las basuras ${ }^{19}$. A pesar de los esfuerzos, estas medidas o no fueron efectivas o no se llevaron a cabo en su totalidad. Es el caso de los varios planes de pavimentación que nunca encontraron buen término. En fechas avanzadas del siglo XIX aún siguen existiendo proposiciones de empedrar la vía pública, además de para embellecer las calles y mejorar el tránsito y habitabilidad de los vecinos, para "la conservación de nuestra bahía, origen de la riqueza pública, que se nos pierde por momentos" 20 .

La cláusula dispositiva del segundo bando particular es muy concisa en su mandamiento: prohíbe tirar la basura en la vía pública y cumplir con lo dictado en el primer bando relativo al sistema de recogida de basuras. También hace mención de los comisarios de barrio como asistentes encargados de la materia de policía, a los cuales se les señala de manera expresa que deberán velar por el cumplimiento de la contrata y de la cooperación vecinal: si el contratista no llevaba a efecto lo estipulado, era compromiso de dichos comisarios efectuar la limpieza de manera urgente mediante el alquiler de carretones -pagados por el asentista-; en contraste, les competía perseguir a los vecinos "inobedientes" que no colaborasen con lo ordenado. Para los contraventores la cláusula penal indica una multa de seis ducados, y en caso de no pagarse o no poder efectuarse, supondría el ingreso en prisión durante el periodo de ocho días.

El segundo bando sugiere una postura más conminatoria al renovar el auto anterior, y en consecuencia, pone de manifiesto la suficiencia de la norma con respecto al cumplimiento. Este caso no es una circunstancia aislada de la capital cubana, en ciudades como México (Dávalos, 1997, p. 56) o Buenos Aires (Sidy, 2011, pp. 51 y 57) también se reiteraban los bandos ante la falta de efectividad. No obstante, Tau Anzoátegui (2004, p. 104-106) señala que la ratificación y repetición de bandos no siempre era un indicio de incumplimiento sino más bien era parte del carácter de esta tipología legislativa, y además, se interpretaba dentro de la labor que tenían estas disposiciones en cuanto a variar conductas y educar al ancho de la población. Estas consideraciones pueden dar lugar entender los bandos particulares

19 Acta de la Junta Extraordinaria mandada por el Marqués de la Torre, Gobernador de La Habana, sobre el estado del puerto. La Habana, 23 de Noviembre de 1772. AGI, PC, Legajo 1228.

20 Informe de Juan Montalvo y José María de Genes, comisarios del empedrado del cabildo habanero, sobre el proyecto de empedrado de Arsène Lacarrière Latour. La Habana, 9 de febrero de 1824. AGI, Ultramar, Legajo 38, Expediente 7. A mitad de centuria también se puede observar un nuevo plan de pavimentación en el que alude a la obligación de proteger el puerto: "La necesidad imperiosa por varios motivos, entre ellos el de preservar a la bahía de este puerto de funestos daños, ha llamado en distintas épocas la atención de este Gobierno acerca del modo de mejorar el estado de las calles de la Ciudad, pero los proyectos que para ejecutarlas se hubieron de formar, sucumbieron siempre ante la falta de recursos para obra de tanto costo": Oficio de Federico Roncali, gobernador de La Habana, al Ministro de Gobernación del Reino. La Habana, 2 de Agosto de 1849. Archivo Histórico Nacional (AHN), Ultramar, Legajo 4635, Expediente 6. 
como un instrumento más específico en su función de control social debido a que era asidua su publicación en comparación de los bandos de buen gobierno.

En contraste de lo anterior, el caso que se analiza revela que el segundo edicto tampoco remedió los contratiempos y pocos meses después el gobernador Ezpeleta volvió a emitir un tercer bando particular ${ }^{21}$ en el que expresaba el estado de la cuestión. La cláusula introductoria informó de la incapacidad del contratista de poder llevar a cabo las condiciones pactadas en la contrata, por lo cual, la parte dispositiva evocó la rescisión del ajuste con el contratista. Se anunció la vacante de un rematador que se hiciese cargo del servicio de recogidas, mientras de un modo provisional correría a cuenta de los comisionados del cabildo en el asunto. Otra novedad que presentó este tercer mandato fue la reformulación de la cuota mensual aplicada al alumbrado y al servicio de recolección porque había sido "demostrable que la cantidad asignada a cada vecino no corresponde al costo [...] que por tentativa se dispuso". En tal sentido, cesó la primera contribución a favor de una nueva que tenía en cuenta la proporción, el equipamiento y el tipo de inmueble que debía contribuir. Se estipuló que las casas altas tenían que pagar ocho reales, cinco las casas bajas con zaguán y tres las que no poseían zaguán, aunque si detentaban carruaje, la tarifa se aumentaba a cuatro. Para los establecimientos públicos, tales como "tiendas de mercaderes, boticas, bodegones y tabernas", el precio también fue de cuatro reales, mientras que la tasa para las puertas accesorias se reducía a un real. El sistema de alumbrado de calles comenzó a tramitarse para su instalación, entretanto, Ezpeleta recordó los artículos de su bando de buen gobierno relativos a la iluminación de la vía pública por algunos particulares y comercios menores. En lo respectivo a la evacuación de deshechos también reiteró las disposiciones anteriores sobre barrer y regar el frente de los hogares en amparo de la salud pública y la conservación de la bahía habanera. No obstante, añadió el menester de no abrir hoyos ni poner piedras en las calles para facilitar el tránsito de las personas y los vehículos. Por último hay que destacar, que al igual que el primero, este bando común no expresó pena alguna para los contraventores que en adelante no pagasen la carga económica de los servicios.

\section{EL REGLAMENTO DE POLICIIA}

Junto con los bandos, en su naturaleza preceptiva y ejecutiva, aparecían también otro tipo de dispositivos documentales de la misma personalidad que regulaban el orden municipal. Es el caso de los reglamentos, soporte que permitía articular en materia de policía sobre uno o varios asuntos concretos sin alcanzar la extensión y alcance temático de los bandos de buen gobierno. Estos eran otro exponente más de la capacidad y detalle que adquiría la ciencia de la policía para orientar las conductas de la vida urbana.

21 Bando particular del gobernador Ezpeleta. La Habana, 23 de Abril de 1787. AGI, PC, Legajo 1407. 
Al hilo del apartado anterior, a pesar de que se ha señalado que los bandos de buen gobierno o los bandos comunes no necesitaban aprobación real, Ezpeleta informó al Ministro de Indias sobre el primer auto por el que exigía el impuesto para establecer un sistema de alumbrado y un servicio de recogida de basuras ${ }^{22}$. La respuesta del Consejo de Indias llegó poco tiempo después de haberse publicado el tercer bando de los que se han examinado. El Fiscal expuso que el gobernador debería de haber consultado al Consejo antes de haber dado inicio al cobro de la tasa porque "las leyes [...] prohíben a todos los magistrados de Indias el poder imponer tributo, derrama o contribución alguna". También cuestionó la claridad del negocio de la contrata del sistema de recogidas en lo concerniente al repartimiento impositivo entre los vecinos y los diversos establecimientos religiosos y militares. Sin embargo, se reconfortó al gobernador de continuar con lo mandado para que "no carezca el público de la comodidad que habrá comenzado a disfrutar", y a su vez, instruyese al Consejo con el expediente íntegro del asunto para darle la providencia más conveniente ${ }^{23}$.

Con este asunto sobre la mesa y la realidad de la vida diaria en La Habana, Ezpeleta replanteó sus medidas con respecto a la higiene urbana. El 19 de diciembre de 1787 dictó un "Reglamento para la limpieza de las calles y sitios públicos" regulando toda cuestión de policía relativa a la salubridad y ordenamiento de la vía pública ${ }^{24}$. El reglamento se compone de 19 artículos que recuerdan a varios puntos de su bando de buen gobierno en los que profundiza y amplia (Apaolaza Llorente, 2016, p. 252). El tono utilizado desde que inicia la cláusula introductoria es esencialmente conminatorio ${ }^{25}$ en requerimiento, nuevamente, de la salud pública y de la conservación del puerto. Su objetivo es poner fin a las malas prácticas de la población y ordenar el espacio público para favorecer el tránsito, la habitabilidad y el ornato. Para ello, la normativa se autoproclama de "invariable" y adquiere una consideración definitiva, pues de cumplirse cada uno de los puntos que propone quedarían solucionados todos los problemas planteados.

22 Oficio de José de Ezpeleta al Ministro de Indias José de Gálvez. La Habana, 9 de Noviembre de 1786. AGI, SD, Legajo 1432.

23 Dictamen del Fiscal del Consejo de Indias. Madrid, 3 de marzo de 1787. AGI, SD, Legajo 1432. Tras este dictamen no se ha encontrado, por el momento, ninguna resolución más del Consejo de Indias al respecto. Debido a que se continuó el tratamiento de la materia y el alumbrado quedó establecido en los años siguientes es posible que el Consejo o bien no recibiese ningún expediente o bien lo aprobase.

24 Reglamento de policía para la limpieza y desembarazo de las calles y plaza de la Ciudad de La Habana, dispuesto y mandado observar con acuerdo de la Junta de Policía, por el Superior Gobierno. Habana, Imprenta de la Capitanía General, 1787. AGI, PC, Legajo 227B. Este reglamento ha sido mencionado de manera anecdótica en otras investigaciones (Apaolaza Llorente, 2016, p. 252; López Denis, r..r, pp. I $\leqslant-10$; Vega García, 2017).

25 " [...] cuyos siguientes artículos deberán observarse sin contravención, como dirigidos al beneficio común, con advertencia de que a la primera omisión que se note, de cuantos comprende, se ejecutará a los inobedientes con las providencias y penas establecidas y que se juzguen oportunas". 
En cuanto al contenido dispositivo, la primera conducta que pretendía erradicar era la de tirar deshechos en la vía pública - artículo - . La basura, como se ha señalado en bandos anteriores, debía ser almacenada en el interior del hogar "el menos tiempo que fuere posible", sin dar posibilidad de ser acopiada indefinidamente. Para proceder a su evacuación se ideó un nuevo sistema -artículos 7 y 8- que consistía en el empleo de carretones particulares o comunes que tenían que ser registrados mediante licencia del Gobierno. Cada individuo tenía el encargo de transportar los desperdicios fuera de los muros de la ciudad en el lugar señalado para ello. Para un eficaz cumplimiento de lo dictado, se formuló que "pondrá el gobierno competentes celadores" y se cobrará una multa de tres ducados a los contraventores, de los cuales, un ducado se entregaría a dichos vigilantes como recompensa. Igualmente, también serían escarmentados con la misma cantidad los propietarios de los carros sin licencia que se alquilaban para el desplazamiento. Por otro lado, se adjudicaron los días martes, jueves y sábado para la limpieza común por parte de todos los vecinos del frente e interior de cada casa. El texto inducía a los habitantes a denunciar a aquellos que no realizasen la tarea dando parte de ello al comisario de barrio correspondiente -artículo 2-. Asimismo, las partes bajas de los edificios comunitarios tenían que asearse en los días fijados pero únicamente de noche -artículo 15-. La pena monetaria alcanzaba tres y cuatro ducados, respectivamente, para los desobedientes.

El contenido de los artículos se hace más específico en su sucesión. Prohíbe que se viertan en las calles micciones y deposiciones, siendo obligación de los residentes crear sumideros particulares y mantenerlos despejados de cualquier entorpecimiento -artículo 3-. Pero aún va más lejos: concedía un especial énfasis al asunto del arrojo de este tipo de materia doméstica desde los cuartos accesorios. Se exigía a los dueños de las casas que permitiesen utilizar las dependencias comunes para aseo a los inquilinos de las accesorias a fin de evitar la citada actividad. En caso de incumplimiento serían los ocupantes los que tendrían que hacer frente a la multa de tres ducados por deber exigir y pactar con el dueño un horario establecido para el aseo -artículo 4-. No se daba cabida a la eventualidad de mantener animales sueltos en la vía pública -artículo 10- y mucho menos que apareciesen muertos. De tal modo, los inquilinos de las casas donde se presentaba un animal fenecido en el frente, estaban obligados a conducirlos a extramuros para su sepultura -artículo 5-. Otros puntos están encaminados a desobstruir las calles para un tránsito más cómodo y adecuado. Para tal fin, artesanos, vendedores o albañiles no podían invadir el espacio público a través del producto de sus actividades. En otras palabras, no podían ejercer sus labores fuera de la puerta del establecimiento, caseta o recinto, ni tampoco tener equipo, herramientas y restos en la calle, en especial las obras de construcción -artículos 9 y 12-. Los vendedores con puesto público tendrían la obligación de poseer un recipiente para depositar los desechos -artículo 11-. Con respecto a los arrieros, no les estaba permitido dejar atrás ningún tipo de material de carga que hubiese caído de sus recuas y obstaculizase el paso -artículo 6-. Otras prácticas a las que se puso impedimento fue el prender hogueras y fuegos en las calles 
-artículo 1 -, y también perseguir a los propietarios que levantasen "el pavimento [...] para regularlo con el de su casa" -artículo 13-. Como se distingue, el reglamento aspiró organizar el espacio público y sus edificaciones. Por último, advierte que los encargados de velar por el cumplimiento de lo expuesto, como delegados de policía, eran los comisarios de barrio en su correspondiente demarcación. A ellos también se les podría hacer imputable los descuidos ante la falta de cumplimiento de algún punto en su circunscripción -artículo 16-. Sin embargo, como se ha anticipado, hubo celadores que eran responsables primeros de dar aviso de cualquier incidencia, a lo que los vecinos también estaban invitados a actuar-artículo 17-. Igualmente, aquellos individuos que no pudiesen hacer efectivo el pago de la multa, que normalmente solía constar de tres ducados, serían dirigidos a la cárcel durante el tiempo proporcionado a su infracción -artículo 18-. El punto final-19- hacía la norma extensiva a todos los vecinos porque "las calles [...] son de uso común a la sociedad".

En términos generales, el reglamento habilitó un nuevo sistema de evacuación de basuras y reformuló la limpieza de calles y casas. Además, contempló cuestiones que se dirigían más allá de la higiene como el buen tránsito y el ordenamiento de la vía pública. Destaca el procedimiento de retirar las basuras fuera de la ciudad, pues en cierta medida, era una vuelta a la situación anterior de lo establecido por los bandos particulares. Las innovaciones surgieron en el método empleado en la evacuación con el uso de carretones específicos y matriculados. Del mismo modo, el texto hace patente una vez más la primacía del beneficio común en detrimento del interés individual a partir de la actuación articulada entre el espacio público y ámbito de lo personal. El reglamento también constituía un incremento de la ocupación en materia de policía. Por un lado, la profundización y ampliación de lo articulado se deduce del carácter de la ciencia de la policía por dedicarse al más mínimo detalle en su objetivo de moldear las costumbres sociales. Por otro lado, también sugiere un aumento de la vigilancia al incluir a celadores específicos e incluso citar a la colaboración de los vecinos para detectar al indisciplinado. De aquí se hace patente el cometido continuado, inmediato y circunspecto de la ciencia de la policía (Fraile, 1997, p. 24).

Este dispositivo articulado concerniente a higiene es muy similar al aparecido en la ciudad de México pocos años después. Durante el gobierno del Conde de Revillagigedo (1789-1794) en el virreinato novohispano, la capital mexicana conoció muchos cambios a nivel urbanístico. El Conde expidió varias provisiones que tenían como consecución mejorar la salubridad y el aspecto de la urbe. Precisamente hay que destacar un reglamento de policía publicado el 31 de agosto de 1790 que se componía de 14 artículos. En él se abordaban cuestiones extremadamente similares a las referidas en La Habana: limpieza de calles, depósito y horario de residuos, prohibición de verter basuras a la vía pública, restricción de animales sueltos o la formación de sumideros, entre otras (Dávalos, 1997, pp. 56 y 57). En este sentido, aunque se tratan de los preceptos más básicos marcados en los tratados de policía, es 
muy posible que el reglamento habanero influyese como modelo en el novohispano con ciertas salvedades relativas a la realidad cotidiana de cada ciudad.

Dado el planteamiento de la normativa reglamentada se puede interpretar que el deseo de Ezpeleta era una consecución de lo establecido a corto o medio plazo. No obstante, la evolución urbanística de La Habana en las décadas siguientes evidencia que los resultados no fueron los esperados-como en el caso de México-. El aspecto de la ciudad no varió y la suciedad permaneció en las calles, de tal suerte, el gobernador llegó a ser incluso imputado en su juicio de residencia por el lamentable estado de suciedad en la capital cubana. Sus sucesores, por ejemplo Luis de las Casas (17901796) o el Conde de Santa Clara (1796-1799), también continuaron haciendo especial hincapié en las cuestiones de salubridad urbana a través de la reglamentación. Sin embargo, cabe decir que la firma de una contrata para la recogida de basuras sirvió de precedente para futuros proyectos del mismo calibre ${ }^{26}$. En contraste, los derroteros de la red de iluminación fueron bien distintos, pues hacía 1789 se habían colocado un total de 920 de faroles distribuidos por los ocho barrios de La Habana. Existieron, empero, algunos individuos interesados en descomponer el alumbrado a través de la destrucción del mobiliario que lo configuraba. Pudo suceder por mero vandalismo o porque la luz importunaba realmente ciertas actividades ilícitas consumadas en la oscuridad nocturna. Este sistema de faros con velas se amplió y se mantuvo vigente en la ciudad hasta la época del general Miguel Tacón, que en la década de 1830 incorporó iluminación por medio de la combustión de aceite (Amores Carredano, 2000, pp. 376-379).

\section{CONGLUSIONES}

La naturaleza de los documentos normativos analizados en este artículo abre un amplio abanico de posibilidades para conocer y estudiar con mayor profundidad determinados aspectos de la vida cotidiana en el ámbito municipal indiano. La documentación referida en el texto exhibe todas las características y atributos formales que se otorgan a este tipo de disposiciones guiadas por la ciencia de la policía. En el caso de los bandos particulares y el reglamento se percibe que son un instrumento idóneo para profundizar y aproximarse a una cotidianidad urbana muy concisa. En el presente estudio se ha percibido que la reiteración en la publicación es signo de adaptabilidad y permeabilidad a unas circunstancias concretas, pero también se contempla como la perseverancia de la policía en el intento de transformar determinadas conductas a través del control social. Sin embargo, los resultados observados a corto y medio plazo manifiestan el fracaso de las medidas debido a la falta de medios eficaces para la instauración de lo mandado y a la ausencia de una vigilancia efectiva para su cumplimiento. En cambio, a largo plazo pudieron servir

26 Oficio de Mariano Ricafort, gobernador de La Habana al Ministro de Gracia y Justicia. La Habana, 26 de febrero de 1833. AHN, Ultramar, Legajo 4602, Expediente 14. 
como el precedente pedagógico que fijó los parámetros de comportamiento racional en el espacio urbano.

Para finalizar, es preciso señalar que aunque los tres bandos particulares y el reglamento reparan en detalles muy valiosos de la vida cotidiana, también sugieren unas conclusiones un tanto limitadas al analizarse bajo un espacio cronológico y una selección documental muy reducidos. Es necesario seguir trabajando sobre el asunto y examinar esta normativa particular en conjunto y en un ámbito espacial y temporal más prolongado para conocer con mayor profundidad diferentes aspectos que se viven en el día a día de la ciudad ilustrada. Lo mismo ocurre con respecto a examinar la evolución urbanística, pues a partir de los tres bandos comunes y el reglamento hay una perspectiva muy acotada del funcionamiento de la materia. Es necesario por ello, reunir e investigar todo tipo de documentación primaria de naturaleza variada para poder desgranar interpretaciones más contundentes con respecto al desarrollo urbano de La Habana o de cualquier otra ciudad hispanoamericana hacia finales del siglo XVIII.

\section{BIBLIOGRAFÍA}

Alzate Echeverri, Adriana María (2007). Suciedad y orden. Reformas sanitarias borbónicas en la Nueva Granada (1760-1810). Bogotá: Universidad del Rosario.

Amores Carredano, Juan Bosco (2000). Cuba en la época de Ezpeleta (1785-1790), Barañáin: EUNSA.

Amores Carredano, Juan Bosco (2019). La 'Instrucción política' del Marqués de la Torre: una mirada crítica de la sociedad habanera del siglo XVIII. Anuario de Historia Regional y de las Fronteras, 25, 1, pp. 103-133.

Anguita Cantero, Ricardo (1997). Ordenanza y policía urbana. Los orígenes de la reglamentación edificatoria en España (1750-1900), Granada: Universidad de Granada.

Apaolaza Llorente, Dorleta (2015). En busca de un poder de policía: los comisarios de barrio y las ordenanzas o reglamento de policía de La Habana de 1763. Temas Americanistas, 34, 2015, pp. 1-24.

Apaolaza Llorente, Dorleta (2016). Los bandos de buen gobierno en Cuba. La norma y la práctica (1730-1835). Bilbao: Universidad del País Vasco.

Apaolaza Llorente, Dorleta (2018). La Habana ilustrada del siglo XVIII; sus transformaciones urbanas a través de la mirada de los bandos de buen gobierno. 'Cambiando el poder'. Iberoamérica Social, 2, pp. 63-80.

Corbin, Alain (1987). El perfume o el miasma. El olfato y el imaginario social, siglos XVIII y XIX. México: Fondo de Cultura Económica.

Dávalos, Marcela (1997). Basura e Ilustración. La limpieza de la Ciudad de México a fines del siglo XVIII. México: Instituto Nacional de Antropología e Historia. 
Alumbrado, limpieza y recogida de basuras en La Habana... - E. Azorín García

Dougnac Rodríguez, Antonio (1994). Manual de Historia del Derecho Indiano. México: Universidad Nacional Autónoma de México.

Escobedo Mansilla, Ronald (1995). El bando de buen gobierno, instrumento de la Ilustración. En Memoria del X Congreso del Instituto Internacional de Historia del Derecho Indiano. México: Universidad Nacional Autónoma de México, pp. 473-495.

Etlin, Richard (1997). L'air dans l'urbanisme des lumières. Dix-huitième siècle, 9, pp. 123-134.

Foucault, Michel (2006). Seguridad, territorio, población. Buenos Aires: Fondo de Cultura Económica.

Fraile, Pedro (1997). La otra ciudad del rey. Ciencia de policía y organización urbana en España. Madrid: Celeste.

Godicheau, François (2013). Orígenes del concepto de orden público en España: su nacimiento en un marco jurisdiccional. Ariadna histórica, no 2, pp. 107-130.

Godicheau, François (2017). Les commissaires de quartier à La Havane: d'une fondation pionnère à la nécessité d'un systéme de pólice (1763-1812). Nuevo Mundo Mundos Nuevos, [En línea]: https://journals.openedition.org/nuevomundo/71265 Consultado el 18/12/2019.

Guerrero, Omar (1986). Las ciencias de la administración en el estado absolutista, México: Fontamar.

Gutiérrez, Ramón (2010). Arquitectura y urbanismo en Iberoamérica. Madrid: Cátedra.

Jori, Gerard (2013). Población, política sanitaria e higiene pública en la España del siglo XVIII. Revista de Geografia Norte Grande, 54, pp. 129-153.

Lempérière, Annick (2008). "República y publicidad a finales del Antiguo Regimen", en François-Xavier Guerra, Annick Lempérière et al., Los espacios públicos en Iberoamérica. Ambiguedades y problemas. Siglos XVIII-XIX, Ed. digital. México: Centro de Estudios Mexicanos y Centroamericanos, pp. 35-51.

López Denis, Adrián (2003). Higiene pública contra higiene privada: cólera, limpieza y poder en La Habana colonial. Estudios interdisciplinares de América Latina y el Caribe, 14, pp. 11-33.

Martínez Gomis, Mario (2003). La noche y los noctámbulos en el siglo XVIII español. En: Ángel Vaca Lorenzo (coord.), Fiesta, juego y ocio en la historia. Salamanca: Universidad de Salamanca, pp. 147-171.

Reguera Rodríguez, Antonio T. (1992). Urbanismo y medioambiente en la España de la Ilustración. Polígonos, 2, pp. 109-137.

Riverend, Julio Le (1992). La Habana, espacio y vida. Madrid: Mapfre.

Segarra Lagunes, Silvia (2012). Mobiliario urbano, historia y proyectos. Granada: Universidad de Granada. 
Sidy, Bettina Laura (2010). El ejercicio del gobierno urbano colonial: apuntes para un análisis de los bandos particulares en la ciudad de Buenos Aires a mediados del siglo XVIII. Revista electrónica del Instituto de Investigaciones Ambrosio L. Gioja, 5, 2010, pp. 120-136.

Sidy, Bettina Laura (2011). Crecimiento y control de la vida urbana. Un análisis de los bandos de gobierno en el Bueno Aires colonial. Cuaderno urbano, 10, 2011, pp. 41-61.

Tau Anzoátegui, Víctor (1983). Los bandos de buen gobierno de Buenos Aires en la época hispánica. En: Actas del VI Congreso del Instituto de Historia del Derecho Indiano. Valladolid: Casa-Museo de Colón, pp. 91-146.

Tau Anzoátegui, Víctor (2004). Los bandos de buen gobierno del Río de la Plata, Tucumán y Cuyo. Época hispánica. Buenos Aires: Instituto de Investigaciones de Historia del Derecho.

Vallejo Fernández, Jesús (2008). Concepción de la policía. Cuadernos de derecho judicial, VII, pp. 117-144.

Vega García, Olga (2017). Una curiosidad en la colección de impresos cubanos del siglo XVIII: el 'Reglamento de Policía para la limpieza y desembarazo de las calles y plazas de la Ciudad de La Havana'. Librínsula, 362, [En línea]: http://librinsula. bnjm.cu/206-393/secciones/362/tesoros/362 tesoros 1 .

html?fbclid=IwAR2V8FUdqBTgYssnimGu87WFEoj0GCK16YiRDmQEU0i1LqOE4 Zmu0IIR_w Consultado el 18/02/2020. 
